\title{
Development of a New Measuring Device AND INTERPRETATION METHODS FOR SPECTRAL INDUCED POLARIZATION (SIP)
}

\author{
Niederteithinger. E.", Radic, T.", Kretzschmar, D.", \& Lienau, R..-
}

\footnotetext{
Buero fuer Geophysik Lorenz, Berlin; Germany, 100577.3003@compuserve.com "Technical University of Berlin, Institut fuer angewandte Geophysik, Berlin, Germany ".Lienau-Industrieelektronik, Berlin, Germany
}

\section{INTRODUCTION}

The SIP (or complex resitivity) method deals with the measurement of the frequency dependent electrical resistivity. Previous investigations of other authors have lead to the following main conclusions:

- SIP is a very useful tool in hydrological, environmental and engineering studies (Knödel et al., 1997). For example recent studies have shown that SIP effects correlate with hydraulic permeability of sediments.

- Most unconsolidated sediments show small IP effects (around 10 times smaller than in mineral exploration). The accuracy of the presently available equipment (developed for conventional IP investigations) isn't sufficient in most cases.

- In contrast to ores shaly sediments show maximum IP effects at frequencies around $100 \mathrm{~Hz}$ and above. Thus an adopted field device must have a maximum frequency of at least $10 \mathrm{kHz}$. Furthermore, electromagnetic effects have to be considered in interpretation.

As a consequence of these conclusions a new measurement device for commercial and scientific use has to be build. In conjunction there's a need for interpretation software considering complex resistivities and electromagnetic effects. 


\section{MEASURING DEVICES}

New measuring devices for laboratory and field use have been built (Radic et al., 1996). They use narrow band sine wave excitation up tp $20 \mathrm{kHz}$. Different transmitters (output max. $2200 \mathrm{Watt}$ ) are available. The analog parts are placed close to the electrodes and connected to the control unit via fiber optical links (Figure 1). Current and voltage (up to eight channels) are digitized and processed on separate DSP boards. Coherency analysis is used to determine the actual measurement values. The modular design allows customization for laboratory and all kind of field use. A comfortable graphical user interfaces for industry standard laptops was programmed. Infield quality control is possible. Figure 2 shows two example resistivity spectra from laboratory samples. Comparison measurements showed a much higher accuracy and better repeatability than conventional instruments.

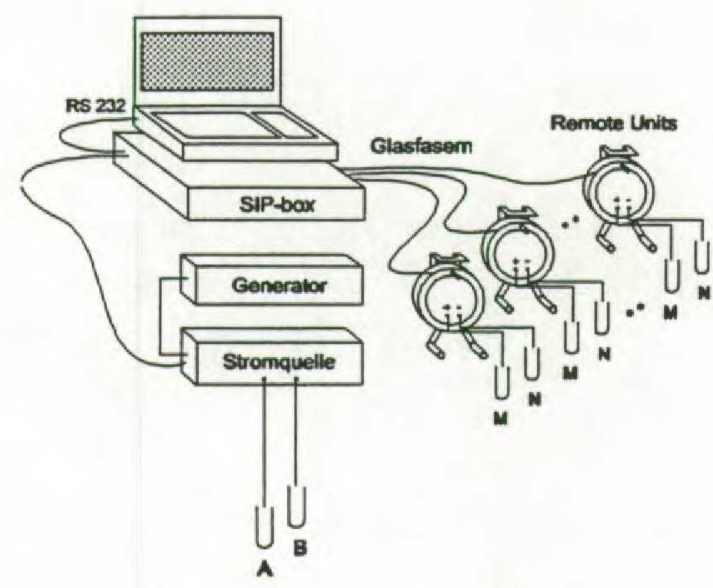

Figure 1: Principle of new SIP field device

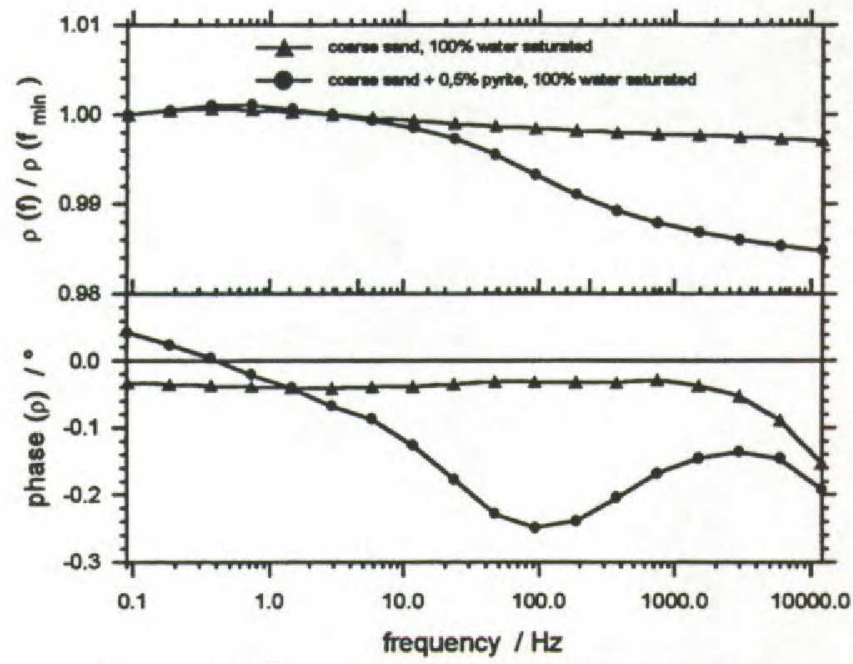

Figure 2: Spectra of laboratory samples (coarse sand without/with low pyrite content)

\section{D INVERSION}

Soundings are still an important type of IP measurements. An ID inversion algorithm has been developed for interpretation (Kretzschmar et al., 1997). The model consists of horizontal layers, each with user defined (for example Cole-Cole type) frequency dependent resistivities. The electrode as well as the cable layout has to be specified. Forward calculations are done in the Hankel transform domain for TE and TM mode. Electromagnetic effects are considered completely this way. Displacement currents are neglected. The results are integrated along the receiver wire with Gauss-Legendre quadrature. Inversion is done by a modified version of the Levenberg-Marquardt algorithm. The high performance and a graphical user interface make the the program a useful tool. The software has been sucessfully tested with synthetic and field data. Even data containing negative IP effects (positive phase values) can be inverted. 


\section{2,5D MODELING}

Where 1D interpretation isn't sufficient 2D or 3D methods are needed. Thus a 2,5D (2D earth, electrode array arbitrary on surface) modeling program was developed.

It bases on a 2D finite difference algorithm used for DC geoelectric modeling (Niederleithinger, 1990). The problem is separated into several smaller ones by spatial Fourier transform in the direction with no variation of subsurface parameters. Matrix equation solving is done by a fast direct method. Complex (Cole-Cole type frequency dependent) resistivities were introduced and

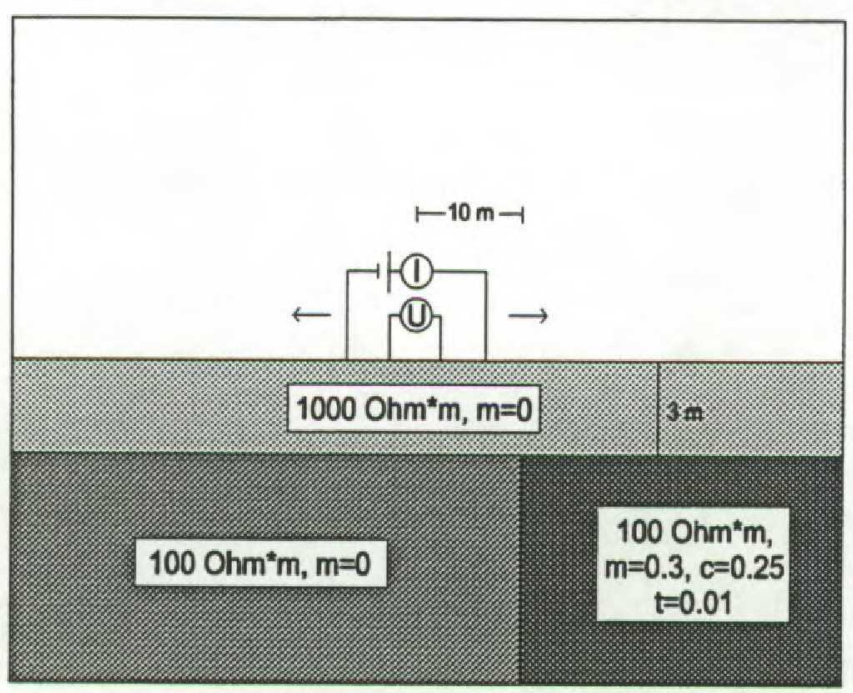

Figure 3: $2 D$ model structure (Schlumberger sounding) the possibility of placing electrodes at arbitrary positions on the surface was added. Accuracy was increased by singularity removal and modified boundary conditions.

The electromagnetic effects are considered by a first order guess (homogenous earth). That is sufficient if the inductive part of the measured potential is smaller than the galvanic.

Comparison with the $1 \mathrm{D}$ program showed good accuracy. Figure 3 and 4 show some example data (Schlumberger sounding over a step model).

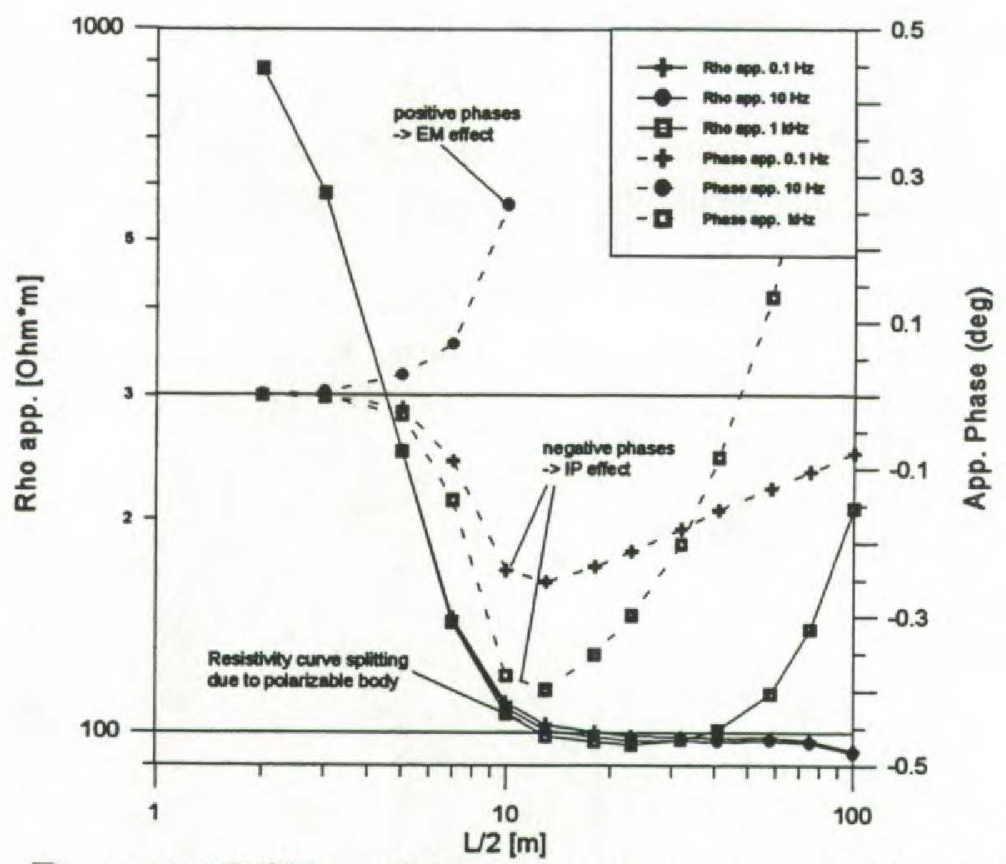

Figure 4: 2D SIP modeling for structure shown in figure 3.

(Schlumberger sounding curves) 


\section{CONCLUSION}

A new measuring device and interpretation software for Spectral Induced Polarization have been developed and sucessfully tested. They can be used for all kind of standard and non standard laboratory and field measurements. We hope that now the door is open for an extended use of SIP in environmental, geotechnical, and hydrological investigations.

\section{ACKNOWLEDGEMENT}

The project was supported by the Deutsche Bundesstiftung Umwelt (German Foundation for the Environment).

\section{REFERENCES}

Knödel, K., Krummel, H., \& Lange, G., 1997: Handbuch zur Erkundung des Untergrundes von Deponien und Altlasten, Band3: Geophysik, Kap. Induzierte Polarisation. Springer, Berlin, in press.

Kretzschmar, D., Niederleithinger, E., \& Radic, T., 1997: Eine 1D-Inversionssoftware zur Interpretation von Messungen der Spektralen Induzierten Polarisation (SIP) in einem besonders weiten Frequenzbereich. Presented at DGG 97 in Potsdam, Germany.

Niederleithinger, E., 1990: Zweidimensionale Modellrechnungen zur Untersuchung oberflächennaher Inhomogenitäten in der Geoelektrik. Diploma thesis, TU Berlin.

Radic, T., Kretzschmar, D., Lienau, R., \& Niederleithinger, E., 1996: Entwicklung eines serienreifen Messgerätes und von Auswerteverfahren fuer hochauflösende Messungen der Spektralen Induzierten Polarisation (SIP). Presented at DGG 96 in Freiberg/Sa., Germany. 